\title{
Evaluation of Regional Knowledge Innovation System in China: An Economic Framework Based on Dynamic Slacks-based Approach ${ }^{*}$
}

\author{
Sheng-Hsiung CHIU ${ }^{1}$, Tzu-Yu LIN ${ }^{2}$ \\ Received: May 26, 2019 Revised: July 17, 2019 Accepted: July 18, 2019
}

\begin{abstract}
The paper proposes a knowledge innovation performance model by the dynamic data envelopment analysis with slacks-based measure approach for evaluating the effectiveness of 30 regional knowledge innovation activities in China from 2010 to 2016 . In recent years, China has paid more attention to knowledge innovation activities, as central and local governments have pushed on with their innovation projects by lots of investment whatever the difficulties may be. Decision-maker is usually interested in judge its knowledge innovation performance relative to target benchmark by exploring whether one provincial administration region performs better among others and/or if the growth of economy will be benefited greatly by the knowledge innovation activities. To acquire the managerial insight about this issue from a comprehensively designed performance evaluation model, knowledge innovation activity is conceptualized as an intertemporal production process. Invention patent and regional gross product are imposed on desirable outputs, highlighting the need for knowledge economy. The empirical result shows that knowledge innovation has a positive effect on economic development. At the same time, decision-maker should be interest in the economic effect of patents' type and quality. The government should then encourage new technical applications with greater commercial value from a market-oriented perspective, in order to benefit the most from the innovation process in the short-run.
\end{abstract}

Keywords: Knowledge Innovation, R\&D Capital Stock, Performance Evaluation, Provincial Administration Region, China

JEL Classification Code: H53, H72; O11; O34.

* The paper was supported by the Department of Education of Guangdong Province [Grant number 2018WTSCX216].

** The paper was presented initially with a title ["Performance Evaluation of the Regional Knowledge Innovation System in China"] at Korea Distribution Science Association (KODISA) 2019 International Conference on Business and Economics (ICBE2019) that was held in Yeosu, South Korea, July 8-10, 2019. The paper has been recognized as one of Distinguished Research Awards at the KODISA.ICBE2019 conference. This paper is a substantially revised and expanded version of the paper presented at the KODISA.ICBE2019 conference. The authors have taken into account all the comments of Editors, Session Chairs and Reviewers in the revised manuscript. The authors greatly appreciate Editors, Session Chairs and Reviewers for their valuable comments, interest in and support of this research.

1 First Author. Associate Professor, Accounting School, Nanfang College of Sun Yat-Sen University, China [Postal Address: 882 Wenquan Road, Wenquan Town, Conghua District, Guangzhou, 510970, China]. Email: mika.bear0809@gmail.com

\section{Introduction}

For a government with its people's welfare in mind, one of the long-term administrative management objectives is to maximize the growth momentum of economic system. As of today, knowledge innovation plays a key role in the highly competitive business, and is therefore could be viewed as one criterion to estimate the extent of the national power. Knowledge innovation and its application, by researching and creating newly practical idea on technological development, facilitate the production and service activities that change inherent human experience. In China, as its market opening up to the world since 1978, there are 120

2 Corresponding Author. Associate Professor, Accounting School, Nanfang College of Sun Yat-Sen University, China [Postal Address: 882 Wenquan Road, Wenquan Town, Conghua District, Guangzhou, 510970, China]. Email: blackmallows@gmail.com

(1) Copyright: Korean Distribution Science Association (KODISA)

This is an Open Access article distributed under the terms of the Creative Commons Attribution NonCommercial License (https://creativecommons.org/licenses/by-nc/4.0/) which permits unrestricted noncommercial use, distribution, and reproduction in any medium, provided the original work is properly cited. 
corporations listed in Fortune Global 500 in 2018, representing that its business activities are more closely tied to the outside world. However, it also becomes more vulnerable to potential challenges from aboard, such as the China-United States trade war. It is the responsibility of the government to strengthen the management of innovation system when intellect property is used to become the best and powerful weapon they have.

As China's economic plan from 2016 to 2020 is carefully outlined in the 13th Five-year Plan, awareness to knowledge innovation application is also embedded in it. Following the guidelines of the 13th Five-year Plan and Made in China 2025 of the central government, each provincial administration regions has its own schemes to encourage industry, institute, and university to invest in knowledge innovation activities, in order to accumulate intelligence capital and/or intellect properties. To this extent, performance evaluation could benefit regulators to improve the efficacy of the policies on innovation activity. Hence, based on its critical role in the economic system, researchers have been trying to measure the innovative performance of national or regional or industrial hierarchies (e.g., Lu, Kewh, \& Huang, 2014; Chen \& Huang, 2016; Kou, Chen, Wang, \& Shao, 2016; Li, Liu, Liu, \& Chiu, 2017; Chen, Lim, \& Zhu, 2018; Lee, Kim, \& Choi, 2019; Jin, Peng, \& Song, 2019); however, literatures on the long-term and dynamic performance evaluation of innovation activity in China is still relatively scant (Chen, Kou, \& Fu, 2018; Xiong, Yang, Guan, 2018; Pan, Ai, Li, Pan, \& Yan, 2019; Wang, 2019).

We try to fill the research gap by examining the innovation performance of Chinese provincial administration regions between 2010 and 2016, under a unified framework of dynamic performance evaluation associated with economic perspective, and identifying whether the innovation system of provincial hierarchy showed considerable quality enhancement of invention patent to be of benefit to their economic growth when the localized boundaries of economic actions are opened under the global trend of trade liberalization. Performance evaluation is a useful managerial instrument to identify the - best or -worst performer, as well as the inefficient source within all selected observations under the specific evaluation framework.

Data envelopment analysis (DEA) is one of the famous methodologies applied in performance evaluation (Lin \& Chiu, 2018). It has already developed several variations of that based on mathematic programming to model a simple or complex framework and obtain practical instructions in response to what the need to be decision-making of modern management environment. A slacks-based measure approach of DEA was firstly proposed by Tone (2001) to introduce a crucial parameter as slacks that measures the difference of specific variables between an efficient and an inefficient in their mathematic programming. After that they continued to extend their concept in processing a problem of performance evaluation with great complexity. Tone and Tsutsui (2010), for example, incorporated the setting of time frame into their SBM approach not only to generalize its evaluation ability from specific time period (i.e. static analysis) to the whole evaluation period (i.e. dynamic series analysis), but also assign some particular characteristic on variables such as discretionary, desirable and undesirable. To explore the effect of innovation activity aggressively driven by China government, we used a dynamic DEA with SBM approach to estimate the efficiency of regional innovation system in China from 2010 to 2016, focusing on the innovative performance from an economic viewpoint, in the hope to shed some light on industrial practices of innovation activity. In addition, we further explored the relationship between invention patents and gross regional product (RGP) to estimate the potential business value of yield on innovative activity.

The remainder of this paper is structured as follows. Section 2 introduces the methodological application of dynamic DEA with SBM approach. The research design of this paper is presented in Section 3. Section 4 is the empirical results for the overall knowledge innovation performance on national, area, and provincial level in China from 2010 to 2016. Finally, section 5 offers conclusions and policy discussions.

\section{Methodology}

Incorporating multiple input and output variables into the unified framework without a strict production function in advance for efficiency and productivity evaluation is the main characteristic of DEA developed by Charnes, Cooper, and Rhodes (1978). It is especially useful to identify the efficient actors among the estimated homogeneous decision-making units (DMUs). Under a DEA framework, multiple inputs and outputs are allowed, which could be beneficial to performance evaluation in various industries (Chiu, Chiu, Chen, \& Fang, 2016). However, the proportional improvement restriction on input/output also limits practical applications using the DEA-CCR model (Charnes et al., 1978) and the DEA-BBC model (Banker, Charnes, \& Cooper, 1984). Tone (2001) then proposed a slacks-based measure (SBM), to make up for the nonproportional inputs or outputs relative to efficient frontier, and it has have been demonstrated to have a wide applicability in practice (Yu \& Lee, 2009; Yu, 2010; Lozano \& Gutiérrez; 2011; Lin \& Chiu, 2013; Chiu \& Lin, 2018). Tone and Tsutsui (2010) also introduced a newly modified 
SBM approach into DEA-based evaluation model with unified calculation framework, namely dynamic-SBM (DSBM) approach, where carry-over variables can be incorporated to link between the consecutive periods. Since both new and accumulated knowledge input could affect knowledge innovation performance, we then adopted the DSBM approach in our knowledge innovation performance evaluation model.

Suppose there were $n$ provincial administration regions (DMUs) $(j=1,2, \ldots, n)$ in China selected in the sample set under an evaluation period of $T$ years $(t=1,2, \ldots, T)$. At each year, $m$ inputs in the input matrix $X(i=1,2, \ldots, m)$ were invested to produce $S$ outputs in the output matrix $Y(i=1,2, \ldots, s)$ from innovation activities of each DMU, where $Y$ represented the good (desirable) output as expected. In addition, a carry-over variable, $Z(i=1,2, \ldots, z)$, was used to connect the relation between two consecutive years. The input-output relationship of each DMU was denoted by $\left(x_{i t}, y_{i t}, z_{i t}\right)$. The non-oriented overall knowledge innovation performance score $\rho_{0}^{*}$ obtained from a dynamic SBM model proposed by Tone and Tsutsui (2010) is defined by Eq. (1) as follow:

$$
\rho_{0}^{*}=\min \frac{\frac{1}{T} \sum_{t=1}^{T} w^{t}\left[1-\frac{1}{m}\left(\sum_{i=1}^{m} \frac{w_{i}^{-} s_{i t}^{-}}{x_{i o t}}\right)\right]}{\frac{1}{T} \sum_{t=1}^{T} w^{t}\left[1-\frac{1}{s+\text { ngood }}\left(\sum_{i=1}^{s} \frac{w_{i}^{+} s_{i t}^{+}}{y_{i o t}}+\sum_{i=1}^{\text {ngood }} \frac{s_{\text {iot }}^{\text {good }}}{z_{\text {iot }}^{\text {good }}}\right)\right]}
$$

subject to

$$
\begin{gathered}
\sum_{j=1}^{n} z_{i j t}^{\text {good }} \lambda_{j}^{t}=\sum_{j=1}^{n} z_{i j t}^{\text {good }} \lambda_{j}^{t+1} \quad(\forall i ; t=1, \ldots, T-1) \\
x_{\text {iot }}=\sum_{j=1}^{n} x_{i j t} \lambda_{j}^{t}+s_{i o t}^{-} \quad(i=1, \ldots, m ; t=1, \ldots, T) \\
y_{\text {iot }}=\sum_{j=1}^{n} z_{i j t} \lambda_{j}^{t}-s_{\text {iot }}^{+} \quad(i=1, \ldots, s ; t=1, \ldots, T) \\
z_{\text {iot }}^{\text {good }}=\sum_{j=1}^{n} z_{i o t}^{\text {good }} \lambda_{j}^{t}-s_{i o t}^{\text {good }}(i=1, \ldots, n g o o d ; t=1, \ldots, T) \\
\sum_{j}^{n} \lambda_{j}^{t}=1 \quad(t=1, \ldots, T) \\
\lambda_{j}^{t} \geq 0, \quad s_{i t}^{-} \geq 0, \quad s_{i t}^{+} \geq 0, \quad s_{i t}^{\text {good }} \geq 0
\end{gathered}
$$

where the vectors $s_{i o t}^{-}$and $s_{\text {iot }}^{\text {good }}$ are slacks parameters particularly in SBM framework corresponded to the excess of inputs and bad (undesirable) output, respectively, while $s_{i o t}^{+}$denoted the shortage of good (desirable) output. By design, when the DMU was efficient, $\rho=1$, and $s_{i o t}^{-}, s_{i o t}^{+}$ and $s_{\text {ioo }}^{\text {good }}$ of that were assigned to zero. For an inefficient DMU, $\rho<1$, and it must look for improvement to reduce the excess of inputs, adjust the carry-over variable under discretionary instruction, and creative more output as they desired. Furthermore, $w$ was a user-specified weight for term $\left(W^{t}\right)$, input $\left(W^{-}\right)$and output $\left(W^{+}\right)$, giving flexibility in dealing with the specific contribution of term, input and output to managerial insight. Therefore, all user-specific weight vectors are need to satisfy the following conditions as Equation (8) as follow:

$$
\sum_{t=1}^{T} w^{t}=T, \quad \sum_{i=1}^{m} w^{-}=m, \text { and } \sum_{i=1}^{s} w^{+}=s
$$

When a proposed knowledge innovation performance framework is constructed and executed by the dynamic DEA with SBM approach, the overall knowledge innovation performance score to each DMU over the whole evaluation period can be obtained as $\rho_{0}^{*}$, which is calculated the optimal solution from Eq.(1) with several limited Eq. (2) to (8). If we would like to identify the specific term knowledge innovation performance score to each DMU as $\rho_{0 t}^{*}$, it can be defined as Eq. (9) as follow:

$$
\rho_{0 t}^{*}=\min \frac{\left[1-\frac{1}{m}\left(\sum_{i=1}^{m} \frac{w_{i}^{-} s_{i t}^{-}}{x_{\text {iot }}}\right)\right]}{\left[1-\frac{1}{s+\text { ngood }}\left(\sum_{i=1}^{s} \frac{w_{i}^{+} s_{i t}^{+}}{y_{i o t}}+\sum_{i=1}^{\text {ggood }} \frac{s_{\text {iot }}^{\text {good }}}{z_{\text {iot }}^{\text {good }}}\right)\right]}
$$

\section{Research Design}

\subsection{Conceptual Framework of Knowledge Inno vation Performance Model}

Innovation activity is commonly treated as an effective strategy to strengthen or maintain competitive advantage and/or to facilitate economic growth whatever it's a nation, a region or an enterprise. Investigating the effectiveness of innovation activity is important for decision-maker to see whether the innovation policies serve their expected 
purposes. Furthermore, past innovative input and experience will possibly contribute to the future success. There, using a comprehensive performance framework which takes multiple indicators and time frame into account for evaluating innovation activity would answer the questions well. We propose a knowledge innovation performance evaluation model with dynamic structure to portray the economic benefit originated from intelligent properties and efforts in innovation activities. China has declared the project named Made in China 2025 as a revolution of industrial industry based on involving in innovation activities. The model treats each provincial administration units as a key element in the social-political pyramid in China, which devises their own policy on innovation activities, and had been included in the empirical sample in literatures (Chen et al., 2018). Through the rated score from the proposed knowledge innovation performance model, we can identify certain provinces that perform very well and can be seen as benchmark for the others.

Griliches (1979) used the knowledge production function (KRF) used to identify the input-output relationship of innovation activities. Our performance evaluation model has followed a similar argument as in Griliches (1979). In the basic innovation process, the full-time R\&D employee work for a specific firm in specific provincial administration region, shall be under the support of government fund (i.e. R\&D expenditure) to create newly technological innovation output as intelligent assets (i.e. patent). The provincial administration region will eventually gain (i.e. regional gross product) from the innovation activity it encouraged. According to Griliches (1979) and Chen et al. (2018), past $R \& D$ experience and expenditure is also beneficial to the novel development of technology for the production of new products or service applications. Therefore, the R\&D capital stock is employed and evaluated as capital asset from the capitalizable concept of accounting theory, considering the principle of capital accumulation and amortization. When a provincial administration region acquires R\&D capital stock, this capital asset come at the accumulation of the annual $R \& D$ expenditure and need to be proportionately expensed over the specific time period by the amortization method which is usually its possible economic life. In summary, the $R \& D$ capital stock is not the precise output of the knowledge production as innovation activities, but it is still to play a significant linkage function between two consecutive yearly knowledge creation process. The conceptual framework of the proposed knowledge innovation performance evaluation model is shown in Figure 1.

\subsection{Variables Selection}

In the model as shown in Fig. 1, the economic effect of knowledge innovation is presumed to be reflected in the regional gross product and the volume of granted invention patent, which were treated as the outputs of knowledge innovation process. Number of full-time R\&D employees and annual R\&D expenditure were treated as two inputs. $R \& D$ capital stock was a carry-over variable to link the two consecutive periods for showing that the cumulative effect is the unique characteristic of knowledge innovation process. The definition of variables selection for the knowledge innovation performance model is summarized in Table 1.

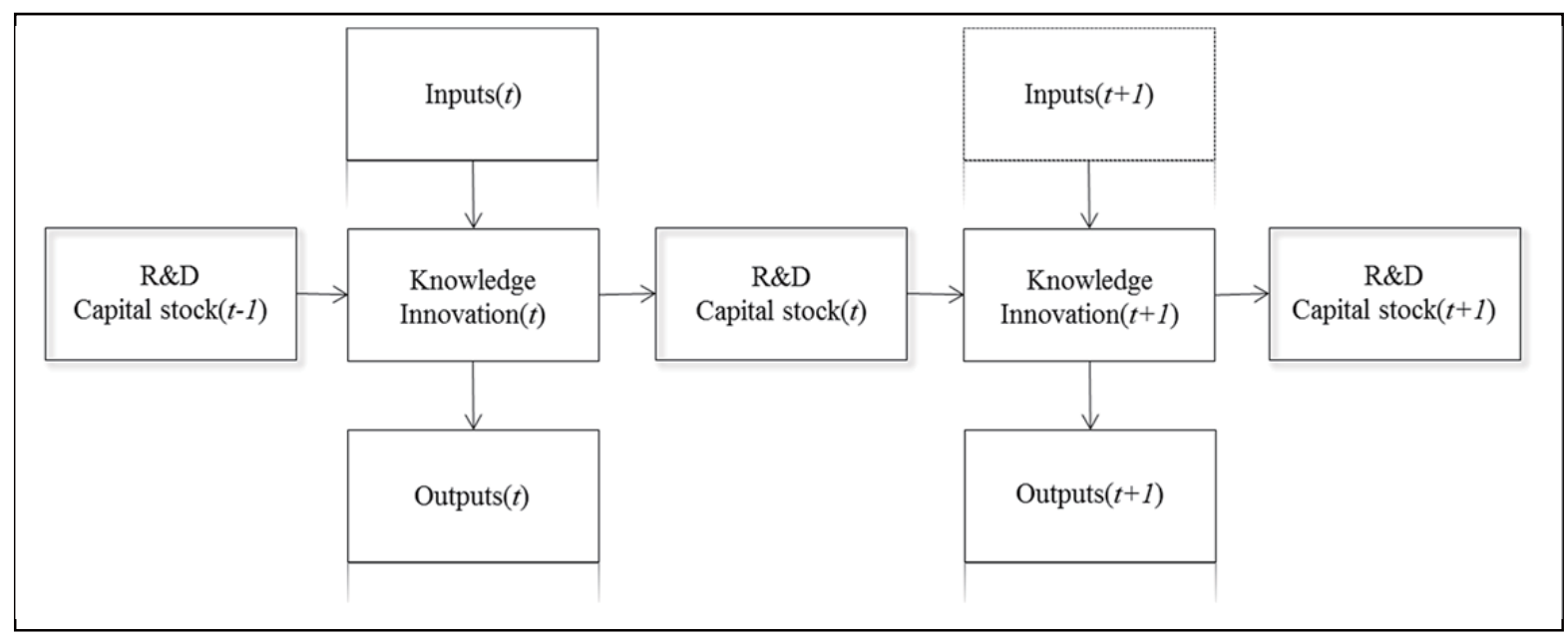

Figure 1: Knowledge innovation performance evaluation model. 
Table 1: Definitions of the input and output variables

\begin{tabular}{|l|l|l|l|}
\hline Variables & \multicolumn{1}{|c|}{ Name } & \multicolumn{1}{|c|}{ Description } & $\begin{array}{l}\text { Measurement } \\
\text { unit }\end{array}$ \\
\hline \multirow{4}{*}{ Input } & $\begin{array}{l}\text { Number of } \\
\text { R\&D } \\
\text { employees }\end{array}$ & $\begin{array}{l}\text { Average full-time R\&D } \\
\text { personnels employed } \\
\text { in a specific year }\end{array}$ & $\begin{array}{l}\text { Thousands } \\
\text { people }\end{array}$ \\
\cline { 2 - 5 } & $\begin{array}{l}\text { R\&D } \\
\text { expenditure }\end{array}$ & $\begin{array}{l}\text { Amount of R\&D } \\
\text { expenditure in a } \\
\text { specific year }\end{array}$ & $\begin{array}{l}\text { Hundred million } \\
\text { RMB dollars }\end{array}$ \\
\hline \multirow{2}{*}{ Carry-over } & R\&D capital & $\begin{array}{l}\text { Amortization cost of } \\
\text { R\&D capital stock }\end{array}$ & $\begin{array}{l}\text { Hundred million } \\
\text { RMB dollars }\end{array}$ \\
\hline \multirow{3}{*}{ Output } & $\begin{array}{l}\text { Regional } \\
\text { gross product }\end{array}$ & $\begin{array}{l}\text { Amount of regional } \\
\text { GDP in a specific year }\end{array}$ & $\begin{array}{l}\text { Hundred million } \\
\text { RMB dollars }\end{array}$ \\
\cline { 2 - 5 } & Patent & $\begin{array}{l}\text { Amount of granted } \\
\text { invention patent }\end{array}$ & Granted case \\
\hline
\end{tabular}

\section{Empirical Results}

\subsection{Sample and Description}

The basic requirement of DEA framework in sample selection is to guarantee the homogeneity of the evaluated DMUs. We are interested in the effectiveness of knowledge innovation activities in China. According to the statistics of world intellectual property organization (WIPO), China has been ranked the second largest source of international patent applications, only lagged behind the United States. Therefore, we focus on the performance behavior of knowledge innovation system in China. Our sample is obtained from the provincial administration region administered by central government. We treated the entire provincial administration regions in China as homogenous DMUs to estimate their knowledge innovation performance from 2010 to 2016. There are 31 provincial administration regions in mainland China, while Taiwan, Hong Kong, and Macau are excluded in our sample set. We had also excluded Tibet due to incompleteness of data. Our final sample then consists of 30 regional administration regions as DMUs.

The data on full-time R\&D employee and R\&D expenditure are collected from the China statistics yearbook on high technology industry, the data on R\&D capital stock is calculated from the instruction proposed by Chen et al. (2018) as Eq. (10) to (12) as follow.

$$
\begin{aligned}
& K_{(t)}=I_{(t-1)}+(1-\delta) \times K_{(t-1)} \\
& K_{(t)}=\sum_{i=0}^{\infty}(1-\delta)^{i} \times K_{(t-(i+1))} \\
& K_{(t)}=\frac{I_{(o)}}{g+\delta}
\end{aligned}
$$

where $K_{t}$ is the calculated R\&D capital stock in the specific $t$ th year. $I_{(t-1)}$ is the gross R\&D expenditure in the $(t-1)$ th year, and the $\delta$ is the depreciation rate. The R\&D capital stock in the period $t$ is a weighted sum of the R\&D investment in the past, which is obtained from Eq. (11), $g$ is the growth rate measured from the $R \& D$ expenditure during the evaluation period. As the evaluation period is from 2010 to 2016, we then use estimate the R\&D capital stock from 2009 as the initial capital stock $K_{0}$, for Eq. (12). We set the depreciation rate to be $10 \%$. The data on regional gross product (RGP) and invention patent were from the China Statistics Yearbook.

From the descriptive statistics of the input, desirable output, and carry-over variables as shown in Table 2 as follows: (Desirable output 1) RGP: The RGP average increased from 14,098.06 and 16,820.71 hundred million RMB dollars between 2010 and 2016. Guangdong has the highest RGP at hundred million RMB dollars in 2016. (Desirable output 2) Invention patent: From 2010 to 2016 the average is 2,381 and 9,510 granted case annually. Jiangsu has the most invention patent in 2016 at 40,952 granted cases. (Carry-over) R\&D capital stock: The R\&D capital stock average is 1337.42 and 2262.5 hundred million RMB dollars between 2010 and 2016. (Input 1) R\&D expenditure: From 2010 to 2016 the average is 227.83 and 505.69 hundred million RMB dollars. Guangdong has spent the most expenditure in knowledge innovation activities in 2016 at 2035.1 hundred million RMB dollars. (Input 2) R\&D employee: The R\&D employee average is 46670 to 87177

\begin{tabular}{|c|c|c|c|c|c|c|}
\hline Year & & RGP & Invention Patent & R\&D capital stock & R\&D expenditure & R\&D employee \\
\hline \multirow[t]{4}{*}{2010} & Min. & 507 & 16 & 15.869 & 1.5 & 378 \\
\hline & Max. & 46013 & 13691 & 5025.3 & 857.9 & 228907 \\
\hline & Mean & 14098.06 & 2381.29 & 1337.42 & 227.83 & 46670.71 \\
\hline & Std. & 11401.29 & 3325.41 & 1329.82 & 259.39 & 58730.53 \\
\hline \multirow[t]{4}{*}{2016} & Min. & 606 & 33 & 18.542 & 2.2 & 208 \\
\hline & Max. & 53210 & 40952 & 8937.8 & 2035.1 & 451885 \\
\hline & Mean & 16820.71 & 9510.2 & 2262.5 & 505.69 & 87177 \\
\hline & Std. & 13216.28 & 11979 & 2442 & 575.79 & 116387 \\
\hline
\end{tabular}
persons involved in knowledge innovation. The most

Table 2: Descriptive statistics 
populated region is Jiangsu at 451885 persons in 2016. In summary, we observe that the average of all variables increased from 2010 to 2016 . The standard deviation of all variables increased, implying the gap of knowledge innovation activities and economic outcome among regions in China are gradually widened. Note that there is a fairly large gap between the maximum R\&D expenditure in 2010 and in 2016.

\subsection{Regional's Knowledge Innovation Performance}

\subsubsection{Empirical Results of Overall}

Table 3 summarized the knowledge innovation performance evaluation results from the dynamic DEA with SBM approach, for all 30 provincial administration regions in China during the period 2010-2016.

Table 3: Comparisons of knowledge innovation performances from 2010 to 2016

\begin{tabular}{|c|c|c|c|c|c|c|c|c|c|}
\hline Province & Score & . & 2010 & 2011 & 2012 & 2013 & 2014 & 2015 & 2016 \\
\hline Guangdong & 1.000 & 1 & 1.000 & 1.000 & 1.000 & 1.000 & 1.000 & 1.000 & 1.000 \\
\hline Beijing & 1.000 & 1 & 1.000 & & 1.000 & 1.000 & 1.000 & 1.0 & 1 \\
\hline Hainan & 000 & 1 & 1.000 & 1.000 & 1.000 & 1.000 & 1.000 & 1.000 & 1.0 \\
\hline Xinji & 0.999 & 4 & 0.999 & 0.999 & 1.000 & 1.000 & 1.000 & & 1.00 \\
\hline Sic & 0.999 & 4 & 0.999 & 0.999 & 1.000 & 000 & 1.000 & 0 & 1.00 \\
\hline Jia & 0.999 & 6 & 0.999 & 0.999 & 0.999 & .999 & 0.999 & 1.000 & 1.00 \\
\hline Shandong & 0.999 & 6 & 0.999 & 0.999 & 0.999 & 0.999 & 0.999 & $9 \mid 1.000$ & 0.99 \\
\hline & 0.999 & 8 & 1.000 & 1.000 & 0.999 & .999 & 0.999 & 9.999 & 0.99 \\
\hline eimongg & 0.999 & 8 & 0.999 & 0.999 & 0.999 & 0.999 & 0.999 & .9 & 0.995 \\
\hline Henan & 0.999 & 10 & 0.999 & 0.999 & 0.999 & 0.999 & 0.999 & 90.99 & 0.995 \\
\hline Liao & 0.943 & 11 & 0.808 & 0.840 & 0.999 & 0.999 & 0.999 & \begin{tabular}{|l|l|}
9 & 1.000 \\
\end{tabular} & 0.99 \\
\hline Zhej & 0.908 & 12 & 0.804 & 0.854 & 0.872 & 0.840 & 1.000 & 1.000 & 1.00 \\
\hline $\mathrm{Gu}$ & 397 & 13 & & 41 & 89 & 0 & & & 1 \\
\hline Yunnan & 0.873 & 14 & 1.000 & 1.000 & 1.000 & 1.000 & 1.000 & 0.686 & 0.57 \\
\hline $\mathrm{Hu}$ & 0.863 & 15 & 0.975 & 0.851 & 0.804 & 40.905 & 0.877 & 70.85 & 0.78 \\
\hline Guiz & 0.858 & 16 & 0.738 & 0.745 & 0.791 & 1.000 & 1.000 & 0.781 & 0.95 \\
\hline Heilon & 0.750 & 17 & 0.795 & 0.837 & 0.917 & 0.753 & 0.724 & 40.643 & 0.62 \\
\hline Shan & 0.743 & 18 & 0.940 & 0.787 & 0.780 & 0.716 & 0.694 & $4 \mid 0.638$ & 0.64 \\
\hline Anhui & 0.717 & 19 & 0.595 & 0.613 & 0.603 & 0.663 & 0.656 & $\begin{array}{ll}6 & 1.000 \\
\end{array}$ & 1.00 \\
\hline Hubei & 0.685 & 20 & 0.705 & 0.658 & 0.689 & 9.678 & 0.681 & 0.691 & 0.690 \\
\hline Jilin & 0.667 & 21 & 0.779 & 0.853 & 0.789 & 0.755 & 0.658 & 0.525 & 0.49 \\
\hline Shaanxi & 0.665 & 22 & 0.649 & 0.750 & 0.764 & 0.709 & 0.712 & \begin{tabular}{|l|}
20.570 \\
\end{tabular} & 0.54 \\
\hline Fujian & 0.633 & 23 & 0.699 & 0.602 & 0.645 & 0.627 & 0.601 & 0.606 & $0.64 \varepsilon$ \\
\hline Chongqing & 0.569 & 24 & 0.615 & 0.695 & 0.679 & 0.628 & 0.550 & 0.438 & 0.41 \\
\hline Shanxi & 0.513 & 25 & 0.530 & 0.607 & 0.580 & 0.500 & 0.510 & 0.491 & 0.43 \\
\hline G & 0.500 & 26 & 0.410 & 0.558 & 0.552 & 0.546 & 0.534 & 40.478 & 0.43 \\
\hline Jia & 0.472 & 27 & 0.461 & 0.589 & 0.624 & 0.556 & 0.504 & 40.365 & 0.3 \\
\hline Qinghai & 0.447 & 28 & 0.226 & 0.312 & 0.454 & 40.390 & 0.561 & 0.999 & 0.746 \\
\hline Tianjin & 0.381 & 29 & 0.538 & 0.455 & 0.439 & 0.397 & 0.356 & 0.272 & 0.27 \\
\hline Ningxia & 0.350 & 30 & 0.214 & 0.288 & 0.353 & 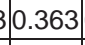 & 0.481 & 0.486 & 0.4 \\
\hline Average & 0.781 & & 0.777 & 0.788 & 0.804 & 40.801 & 0.803 & 30.784 & 0.76 \\
\hline
\end{tabular}

The average performance score for the overall knowledge innovation is 0.781 , with a range from 0.350 to 1.000 . Generally speaking, a stable variation of the average knowledge innovation performance over the whole period around 0.800 seems to decision-maker an information that there is still considerable room for improvement, that is, the policy directive should be to enhance the quality of knowledge innovation, which would then translate to the number of invention patent. From Table 3, we also observe three provincial regions, Guangdong, Beijing, and Hainan, can be categorized as efficient (e.g. score equal to 1), while seven other provincial regions running closely behind them (e.g. rank 4 to 10). In contrast, thirteen provincial regions have relatively worse performances below the mean. Ningxia is inefficient with the overall knowledge innovation performance score at 0.350 , which means it should pay more attention on these important issue of knowledge innovation and make a lot of effort on their policy direction to build up a suitable environment for knowledge incubation.

\subsubsection{Empirical Results of East Area}

Based on the instruction of area classification from Zhang, Luo, and Chiu (2019), we allocate all 30 provincial administration regions (DMUs) into three areas: the east, the central, and the west, respectively, as shown in Table 4. From Table 4, we can see that the east did better than other areas in the knowledge innovation activities from 2010 to 2016, with the overall performance score of 0.873 . In the east area, Guangdong, Beijing, and Hainan are only three efficient regions to benefit from the economic fruits of scientific and technological achievements, as their knowledge innovation score are 1 . One should note that talent, high-tech enterprise, and economic activities were more focused in the east area, and thus could contributed to the area difference. In addition, Shandong, Jiangsu, and Hebei had to work hard to keep up. Alternately, Shanghai, Fujian, and Tianjin are more inefficient among east area regions. Shanghai's innovation perforamnce score posed as a warning sign to policy makers, and showed there could be more improvements to be madein the future.

\subsubsection{Empirical Results of Central Area}

Table 4 also showed 8 regions in the central area in China. We find that half of regions' performance score belongs to the lower middle class. Henan outperforms others in knowledge innovation activity, as its performance score is close to 1 . Hunan and Heilongjiang has higherthan-average perforamnce score . It also should be noted that the average performance score of the central area is 
the worst, comparing to other areas, showing that there are more rooms to improve in its knowledge innovation.

\subsubsection{Empirical Results of West Area}

There are 11 regions in the west area in China. Half of them have higher-than-average performance score. The performance scores of the Xinjiang, Sichuan, and Neimonggol are all close to 1 , but the overall knowledge innovation performance score of Chongqing is merely 0.569 , well below the average in the west area (Table 4).

Table 4: Comparisons of the overall knowledge innovation performances by area

\begin{tabular}{|c|c|c|c|}
\hline Area & Province & Score & Rank \\
\hline \multirow[t]{11}{*}{ East } & Guangdong & 1.000 & 1 \\
\hline & Beijing & 1.000 & 1 \\
\hline & Hainan & 1.000 & 1 \\
\hline & Shandong & 0.999 & 6 \\
\hline & Jiangsu & 0.999 & 6 \\
\hline & Hebei & 0.999 & 8 \\
\hline & Liaoning & 0.943 & 11 \\
\hline & Zhejiang & 0.908 & 12 \\
\hline & Shanghai & 0.743 & 18 \\
\hline & Fujian & 0.633 & 23 \\
\hline & Tianjin & 0.381 & 29 \\
\hline East (Mean) & & 0.873 & \\
\hline \multirow[t]{8}{*}{ Central } & Henan & 0.999 & 10 \\
\hline & Hunan & 0.863 & 15 \\
\hline & Heilongjiang & 0.750 & 17 \\
\hline & Anhui & 0.717 & 19 \\
\hline & Hubei & 0.685 & 20 \\
\hline & Jilin & 0.667 & 21 \\
\hline & Shanxi & 0.513 & 25 \\
\hline & Jiangxi & 0.472 & 27 \\
\hline Central (Mean) & & 0.708 & \\
\hline \multirow[t]{11}{*}{ West } & Xinjiang & 0.999 & 4 \\
\hline & Sichuan & 0.999 & 4 \\
\hline & Neimonggol & 0.999 & 8 \\
\hline & Guangxi & 0.897 & 13 \\
\hline & Yunnan & 0.873 & 14 \\
\hline & Guizhu & 0.858 & 16 \\
\hline & Shaanxi & 0.665 & 22 \\
\hline & Chongqing & 0.569 & 24 \\
\hline & Gansu & 0.500 & 26 \\
\hline & Qinghai & 0.447 & 28 \\
\hline & Ningxia & 0.350 & 30 \\
\hline West (Mean) & & 0.742 & \\
\hline
\end{tabular}

The results indicate that Chongqing may not be efficient in knowledge innovation activity during this period. Though there was abundant R\&D budget and human resources, attracting research institutes and enterprises, yet it still didn't reflect in the efficiency score. Enhancing the quality of invention patents could be one way to improve its knowledge innovation performance.

\subsection{Knowledge Innovation and Economic Performance}

Table 5 demonstrates the estimation results of the effect of knowledge innovation output on economic performance by two proposed panel regression model with regional and annual fixed effect. Model 1 is to show the effect of the number of firm, the number of granted patent, and the knowledge stock evaluated in Eq. (10) to (12) in section 4.1, on economic performance. We can observe that Firm and Patent have positive and significant effects on economic performance, while the knowledge stock being not significant. The further direct effect of knowledge innovation output on economic performance could be estimated by Model 2, and it revealed that if a nation/region with more knowledge innovation output such as invention patents and utility model patents, those could reflect better on economic performance.

Table 5: The results of regression model

\begin{tabular}{|c|c|c|}
\hline Variable & Model 1 & Model 2 \\
\hline \multirow[t]{2}{*}{ Firm } & $0.176^{\star * \star}$ & $0.134^{* * *}$ \\
\hline & $(4.022)$ & $(2.953)$ \\
\hline Region & YES & YES \\
\hline Year & YES & YES \\
\hline \multirow[t]{2}{*}{ Constant } & $6.778^{\star \star \star}$ & $6.833^{\star \star \star}$ \\
\hline & $(13.456)$ & (13.726) \\
\hline \multirow[t]{2}{*}{ Patent } & $0.071^{\star \star \star}$ & \\
\hline & $(3.078)$ & \\
\hline \multirow{2}{*}{ Knowledge Stock } & -0.008 & -0.013 \\
\hline & $(-0.476)$ & $(-0.782)$ \\
\hline \multirow{2}{*}{ Invention Patent } & & $0.053^{\star *}$ \\
\hline & & $(2.246)$ \\
\hline \multirow{2}{*}{$\begin{array}{l}\text { Utility Model } \\
\text { Patent }\end{array}$} & & $0.076^{\star * \star}$ \\
\hline & & $(2.930)$ \\
\hline \multirow{2}{*}{ Design Patent } & & 0.012 \\
\hline & & $(1.188)$ \\
\hline $\mathrm{N}$ & 210 & 210 \\
\hline$\triangle R^{2}$ & 0.952 & 0.958 \\
\hline
\end{tabular}

Note: $\star \star *: p<0.01, * \star: p<0.05, *: p<0.10$; The number in parentheses is the $t$ value

There are two particularly noteworthy findings in Table 5. First, the positive and statistically significant relationship between invention patent, utility model patent and economic performance encourages governments to strengthen the support in knowledge innovation project. Specifically, because the utility model patent refers to a new technical solution for practical use of the shape, structure or combination of the product, the larger estimated coefficient 
for utility model patent could suggest than that it reflects better in economic outcome in the short term. Second, though invention patents take more R\&D investment, people, and time to obtain, yet form our analysis, it indicated that a large number of the granted invention patents cannot be properly translated to the economic growth.

\section{Conclusion}

The main purpose of this paper is to explore the effectiveness of knowledge innovation performance in provincial administration regions in China over the period from 2010 to 216, as China who being the second in the international patent applications. In our knowledge innovation evaluation model based on the dynamic DEA with SBM approach, we translate the inputs of talent and expenditure into desirable outputs of intellectual properties and economic growth. The evaluation results can provide more information on present trend of the knowledge innovation performance, and can help to identify the DMUs whose knowledge innovation need more improvement.

There are two main findings from the evaluation results as follow. First, the average of overall knowledge innovation performance score is around 0.8 , which did not vary much across the time period in the model, while the full-time R\&D employees (input of knowledge innovation process) increased significantly more than the regional economic growth and granted patents. This gap implies that the governments should place emphasis on the quality of knowledge innovation, improving the creativity in the R\&D process. Second, from the regression analysis, we showed that the quantity of utility model patents translates into economic value better. The government should then encourage new technical applications with greater commercial value from a market-oriented perspective, in order to benefit the most from the innovation process in the short-run.

\section{References}

Charnes, A., Cooper, W. W., \& Rhodes, E. (1978). Measuring the efficiency of decision making units. European Journal of Operational Research, 2, 429-444. https://doi.org/10.1016/0377-2217(78)90138-8

Chen, P. C., \& Hung, S. W. (2016). An actor-network perspective on evaluating the R\&D linking efficiency of innovation ecosystems. Technological Forecasting and Social Change, 112, 303-312. https://doi.org/10.1016/j.techfore.2016.09.016
Chen, K., Kou, M., \& Fu, X. (2018). Evaluation of multiperiod regional R\&D efficiency: An application of dynamic DEA to China's regional R\&D systems. Omega, 74, 103114. https://doi.org/10.1016/j.omega.2017.01.010

Chen, X., Liu, Z., \& Zhu, Q. (2018). Performance evaluation of China's high-tech innovation process: Analysis based on the innovation value chain. Technovation, 74-75, 42-53. https://doi.org/10.1016/j.technovation.2018.02.009

Chiu, C. R., Chiu, Y. H., Chen, Y. C., \& Fang, C. L. (2016). Exploring the source of meta-frontier inefficiency for various bank types in the two-stage network system with undesirable output. Pacific-Basin Finance Journal, 36, 113. https://doi.org/10.1016/j.pacfin.2015.11.003

Chiu, S. H. \& Lin, T. Y. (2018). Performance evaluation of Taiwanese international tourist hotels: Evidence from a modified NDEA model with ICA technique. Technological and Economic Development of Economy, 24, 1560-1580. https://doi.org/10.3846/tede.2018.3116

Griliches, Z. (1979). Issues in assessing the contribution of R\&D to productivity growth. Bell Journal of Economics, 10, 92-116. https://doi.org/10.2307/3003321

Jin, P., Peng, C., \& Song, M. (2019). Macroeconomic uncertainty, high-level innovation, and urban green development performance in China. China Economic Review, 55, 1-18. https://doi.org/10.1016/j.chieco.2019.02.008

Kou, M., Chen, K., Wang, S., \& Shao, Y. (2016). Measuring efficiencies of multi-period and multi-division systems associated with DEA: An application to OECD countries' national innovation systems. Expert Systems with Applications, 46 , 494-510. https://doi.org/10.1016/j.eswa.2015.10.032

Lee, J., Kim, C., \& Choi, G. (2019). Exploring data envelopment analysis for measuring collaborated innovation efficiency of small and medium-sized enterprises in Korea. European Journal of Operational Research, 278 , 533-545. https://doi.org/10.1016/j.ejor.2018.08.044

Lin, T. Y., \& Chiu, S. H. (2013). Using independent component analysis and network DEA to improve bank performance evaluation. Economic Modelling, 32(5), 608616. http://doi.org/10.1016/j.econmod.2013.03.003

Lin, T. Y., \& Chiu, S. H. (2018). Sustainable performance of Low-Carbon Energy Infrastructure Investment on Regional Development: Evidence from China. Sustainability, $10,4657$. https://doi.org/10.3390/su10124657

Lin, L. B., Lin, B. L., Liu, W. L., \& Chiu, Y. H. (2017). Efficiency evaluation of the regional high-tech industry in China: A new framework based on meta-frontier dynamic DEA analysis. Socio-Economic Planning Sciences, 60, 24-33. https://doi.org/10.1016/j.seps.2017.02.001 
Lu, W. M., Kweh, Q. L., \& Huang, C. L. (2014). Intellectual capital and national innovation systems performance. Knowledge-Based $\quad$ Systems, 71, 201-210. https://doi.org/10.1016/j.knosys.2014.08.001

Lozano, S., \& Gutiérrez, E. (2011). Slacks-based measure of efficiency of airports with airplanes delays undesirable output. Computers \& Operational Research, 38, 131-139, https://doi:10.1016/j.cor.2010.04.007.

Pan, X., Ai, B., Li, C., Pan, X., \& Yan, Y. (2019). Dynamic relationship among environmental regulation, technological innovation and energy efficiency based on large scale provincial panel data in China. Technological Forecasting and Social Change, 144, 428-435. https://doi.org/10.1016/j.techfore.2017.12.012

Tone, K. (2001). A slacks-based measure of efficiency in data envelopment analysis. European Journal of Operational Research, 130, 498-509. https://doi.org/10.1016/S0377-2217(99)00407-5

Tone, K., \& Tsutsui, M. (2010). Dynamic DEA: A slacksbased approach. Omega, 38, 145-156. https://doi:10.1016/j.omega.2009.07.003

Wang, D. D. (2019). Performance assessment of major global cities by DEA and Malmquist index analysis. Computers, Environment and Urban Systems, 77, 101365. https://doi.org/10.1016/j.compenvurbsys.2019.101365
Wu, H., Li, S., Ying, S. X., \& Chen, X. (2018). Politically connected CEOS, firm performance, and CEO pay. Journal of Business Research, 91, 169-180. https://doi.org/10.1016/j.jbusres.2018.06.003

Xiong, X., Yang, G. L., \& Guan, Z. C. (2018). Assessing R\&D efficiency using a two-stage dynamic DEA model: A case study of research institutes in the Chinese Academy of Sciences. Journal of Informetrics, 12, 784-805. https://doi.org/10.1016/j.joi.2018.07.003

Yu, M. M. (2010). Assessment of airport performance using the SBM-NDEA model. Omega, 38, 440-452. https://doi:10.1016/j.omega.2009.11.003.

Yu, M. M., \& Lee, C. Y. (2009). Efficiency and effectiveness of service business: Evidence from international tourist hotels in Taiwan. Tourism Management, 30, 571-580. https://doi:10.1016/j.tourman.2008.09.005.

Zhang, B., Luo, Y., \& Chiu, Y. H. (2019). Efficiency evaluation of China's high-tech industry with a multiactivity network data envelopment analysis. SocioEconomic Planning Sciences, 66, 2-9. https://doi.org/10.1016/j.seps.2018.07.013

Zhang, C. (2017). Political connections and corporate environmental responsibility: Adopting or escaping? Energy Economics, 68, 539-547. https://doi.org/10.1016/j.eneco.2017.10.036 